Watson, E. (2020). \#Education: The Potential Impact of Social Media and Hashtag Ideology on the Classroom

\title{
\#Education: The Potential Impact of Social Media and Hashtag Ideology on the Classroom
}

\author{
Ellen Watson* \\ University of Alberta \\ *Corresponding Author: ellen.watson@ualberta.ca \\ Received : 2019-06-10 \\ Rev. Req. : 2020-04-13 \\ Accepted : 2018-04-25 \\ DOI: $10.46303 /$ ressat.05.02.3
}

How to cite this paper: Watson, E. (2020). \#Education: The potential impact of social media and hashtag ideology on the classroom. Research in Social Sciences and Technology, 5(2), 40-56. doi.org/10.46303/ressat.05.02.3

\begin{abstract}
Common on social media platforms, the hashtag (\#) organizes users' ideas, emotions, and comments. Originally used to create a searchable platform, the hashtag and its ideology present interesting considerations for changes to education. As students using social media today most certainly use hashtags to converse, hashtag-informed teaching could connect education to students' worlds instead of forcing students to fit into the pre-defined world of education. Prevalent in post-secondary education, K-12 educators have recently begun to integrate social media tools into their classrooms, but what are the pedagogical implications of the ideologies of these tools? In response, this study asked the following question: "How can the hashtag inform the K-12 classroom?" Using a systematic literature review and thematic analysis, this study analyzed eight articles that discussed the use of hashtags with K-12 students. Findings indicated four themes that could inform the alignment of K-12 classrooms with hashtag ideology: encouraging voice and user-generated content, the potential of selforganization, network hetero/homogeneity, and connecting to space without a common physical space. Suggestions are provided as to how classrooms (and education) may consider restructuring to better reflect hashtag ideology, meeting students in their social media-driven world.
\end{abstract}

Keywords: Hashtag, Social Media, Educational Change

\section{Introduction}

Social media technologies such as Twitter have become an integral part of society. Launched in 2006, Twitter connects users with short, 140-character messages (recently increased to 280character messages) called tweets (Reed, 2013). Using these short messages and running feeds, Twitter connects users across the globe. There are 328 million monthly users with over 500 million tweets sent per day. Above that number, Twitter's website highlights that over 3,600 employees from around the world are using Twitter in a business aspect. It has also been found that approximately 50 percent of students aged 13-17 use Twitter (Science Daily, 2017). Clearly, social media has infiltrated our society and is making its mark on our culture. 
Watson, E. (2020). \#Education: The Potential Impact of Social Media and Hashtag Ideology on the Classroom

Social media makes connecting with others easier than ever; many platforms, including Twitter, allow users to facilitate and organize information using hashtags, encouraging users to combine and develop knowledge as a group while connecting with others. Unfortunately, education has neglected to see beyond the mere communicative process of Twitter, ignoring the principles and possible impacts that Twitter's structures of communication might have on curricula. Analyzing and recognizing the ideologies and social structures informing the everyday world of our students, such as those connected to social media, could provide direction for us to create a structure of schooling that better serves the students of today's world.

Twitter's organization and messaging structures have revolutionized world communication and thinking; specifically, the hashtag has been positioned as a point of association, organization, unification, and polarization. Youth use hashtags every day on social media platforms as a way to connect. Yet, schooling remains unchanged, ignoring those principles brought to culture by the hashtag. By ignoring the pedagogical implications of social media, "education [risks becoming] unworldly and the world [risks becoming] non-educational," (Illich, 1972, p. 24). Students need a relatable world, but, more importantly, they need an education they can relate to the world. Teaching through social media ideologies, such as those associated with the hashtag, could bring this revolution to the K-12 classroom; this article aims to show how classrooms might change to incorporate the ideologies informing a hashtag to better meet their clientele today.

\section{Social Media Use in Education}

Educational research has extensively studied the use of hashtags with both teachers and postsecondary students. The majority of research investigating the use of social media (including the use of hashtags) has been conducted in higher education (Kimmons et al., 2018; Tang \& Hew, 2017). Recently, there has also been a surge of studies investigating K-12 teachers' use of social media (and hashtags) for professional development (e.g., Coleman et al., 2018; Duffy et al., 2018; Meredith, 2018; Rosell-Aguilar, 2018; Willet, 2019). In these studies, it has been claimed that the use of hashtags facilitates the communication of content and provides the ability to connect with and to others and information. However, high school is a very different context than post-secondary education or the professional development of adult learners.

Few studies in peer-reviewed literature focus on social media (e.g., Twitter) as it can be connected to K-12 classrooms. Studies have shown the benefits of connecting social media use to K-12 curricula (Kilinc et al., 2012) and the increase in teacher-student communication offered by social media (Vasquez Cano, 2012). Twitter, specifically, has been shown to improve students' engagement with a subject (Loomis, 2018). Studies have also shown that using social media in younger classrooms can be problematic as students need time to learn how to appropriately use the platform, particularly if they have never participated in social media (Gunuc et al., 2013). Largely, as with studies in post-secondary and professional development 
contexts, research in $\mathrm{K}-12$ has focused on analyzing how social media has been used and the benefits of its use to teaching and learning.

The use of social media (such as Twitter, where the hashtag originated) has been shown to be beneficial in K-12 contexts, but the implications of the ideologies behind this modality have been largely ignored by researchers. In response to this gap in the literature, this study endeavored to view connections between the hashtag and education from a different lens: how the ideology and use of the hashtag on social media might inform classroom structure in $\mathrm{K}-12$ schools. By analyzing those studies that have investigated hashtag use, this research was able to extend beyond analyzing the use of the hashtag in schools and theorize about how we might apply the principles of hashtagged communication to classroom structure and organization.

\section{What is a Hashtag?}

While hashtags today appear on many social media spaces such as Twitter, Facebook, and Instagram, it was on Twitter on August 23, 2007, that users began attaching metadata (a.k.a. hashtags) to tweets (Bates, 2013). Attaching the "\#" symbol in front of a word (or non-spaced phrase) creates a hashtag; for example, \#Groundhogday is read "hashtag Groundhog Day". Originally used to mark topics and searchable keywords (Lu, 2014), the \# (or hash) symbol today often indicates emotion, sarcasm, connection to an event or place, and more. By attaching a hashtag, a user gives an idea a boundary and a focus (Jeffares, 2014) while also informing other users about what they are discussing. On top of this, those following hashtagged conversations are able to choose with what information they want to interact by selecting those hashtags they are curious about and want to learn from (Bates, 2013). The hashtag is ubiquitous across all social media platforms; knowing how to "think in hashtags" (as put by Gleason, 2018) is a skill learned beyond a specific social media platform. This is a very different way of conversing than that occurring in K-12 classrooms today.

Participants in classroom conversations are students, generally similar in their geographical location and age. While these students can choose with whom they want to be friends, they cannot choose with whom they are classmates. The teacher, curriculum, and textbook often dictate what is learned; the student does not choose the information with which they want to interact. Even with the introduction of inquiry activities and student choice, classrooms still have a particular learning goal in mind. Hashtagged conversations have no specific goal to achieve. Students use hashtags in their daily life, yet K-12 classrooms operate differently than social media spaces. Thus, this article sought to answer this question: "How might a K-12 classroom look if informed by ideals implied by hashtags?"

\section{Methods}

\section{Design}

Systematic review procedures were used to search, select, and extract data from studies and articles that met eligibility criteria for this study. An approach that uses secondary-level analysis 
Watson, E. (2020). \#Education: The Potential Impact of Social Media and Hashtag Ideology on the Classroom

to review existing research in light of a new question (Newman \& Gough, 2019), the advantage of a systematic review is that it clearly defines the protocols and search methods used to identify studies relevant to the research question being posed. Using these identified studies, findings can be synthesized to produce results that answer a question for which research is not readily available.

Systematic reviews require a rigorous, methodical, and transparent approach to their search of the literature. Following a systematic review process (as described by Newman \& Gough, 2019) requires the researcher to (1) pose a question, (2) identify assumptions, (3) develop search procedures and criteria, (4) search and select studies meeting criteria, (5) code studies, and (6) synthesize results. To meet steps (1) and (2) in Newman and Gough's process, this study sought to answer the question, "How might a K-12 classroom look if informed by ideals implied by hashtags?" by extending findings from those studies already published that explored the use of hashtags in K-12 education. Recognizing a subjectivist epistemology and relativistic ontology, the findings from this research are interpreted from the perspective of the researcher. It should also be noted that these findings represent interpretations from studies that have been published in peer-reviewed work since there may be research beyond articles in peer-reviewed journals that could have supported or refuted these findings; however, to create a manageable search, and as these studies have been shown to meet the quality standard of the academy, this study was limited to peer-reviewed work.

\section{Search Procedures, Criteria, and Study Selection}

Five electronic databases were used to identify eligible articles: Education Research Complete (EBSCOhost), ERIC, Proquest, PsychINFO, and Sage Journals Online (Education database only). A keyword search within each electronic database was conducted with the word "hashtag" to be found in the title or abstract of a paper (as this eliminated studies discussing hashtags in passing and not as a focus of their article). The keyword "education" was added to the search terms as a second term when the database did not allow researchers to limit results to education-specific journals. Hand searching of reference lists of articles identified during the search process occurred after exhausting all five databases. Titles and abstracts of articles found through the search procedures were screened for relevance. If the article appeared to fit the eligibility requirements, or if it appeared to have the potential to fit these requirements, the full-text document was obtained and screened to determine inclusion.

Decisions for selection were based on the following eligibility criteria: peer-reviewed, empirical study, conducted with primary or secondary students, and providing results on hashtag use or theorizing on the influence of hashtag use. Studies were not restricted to any timeframe, but no studies were found using the search parameters before 2010. Only English language articles were considered. 
Watson, E. (2020). \#Education: The Potential Impact of Social Media and Hashtag Ideology on the Classroom

\section{Data Analysis Procedures}

Studies that met inclusion criteria were read and themes speaking to the question, "How might a K-12 classroom look if informed by ideals implied by hashtags?" noted. Using a thematic analysis approach per Braun and Clarke (2006), those studies identified as meeting the selection criteria were analyzed by (1) familiarizing oneself with the data (i.e., thoroughly reading identified articles), (2) generating initial codes, (3) searching for themes, (4) reviewing themes and coding, (5) defining and naming the themes, and (6) describing the theme for reporting. As each identified article was read thoroughly, initial codes were generated; these included: confirmation bias, diverse connections, constructing and contributing to knowledge, online space navigation and search terms, learning hashtags, online presence, location, sharing information without conversing, and user-generated content. Codes were analyzed and collapsed into four overarching themes that spoke to hashtag ideals in the classroom: giving voice to students, self-organization and emerging knowledge, homophily and heterogeneity, and space beyond place. Using these four themes, the researcher re-read each identified article to assess connections of existing codes to each theme. Finally, themes were defined using the coded findings and a description of each theme written.

\section{Findings and Discussion}

Titles and abstracts of 200 citations retrieved from electronic searches of databases were reviewed. Of those, the full texts of 15 articles were retrieved and screened for inclusion as they potentially met the criteria for this study. Eight of these articles met the eligibility criteria. Common reasons for article rejection included: not education-focused $(n=60)$, post-secondary populations $(n=40)$, teacher or administrator development focus $(n=26)$, and metric prediction or measurement $(n=17)$. Other reasons for article rejection included: not written in English, methodology focused, and public movement analysis. Arguably, this is a small sample for literature analysis on this topic, yet this also highlights the need to analyze the implications of the hashtag in secondary education.

\section{Overview of Article Findings}

Of those articles that conducted formal studies $(n=6)$, four reported secondary student participants, with one (Gleason, 2018) starting the research with secondary students and completing the study with these students in college. All of these articles included student voice within their findings. The representation of these voices included students describing their interaction with hashtags (e.g., Gleason 2016, 2018; Jimenez, 2016) and a representation of tweets from students (e.g., Gleason, 2016, 2018; Journell et al., 2013, 2014). There were no articles using primary school-aged participants, likely due to Twitter requiring users to be age 13 or older.

Some articles presented a strong focus on hashtags and their educational implications (e.g., Gleason, 2013, 2016, 2018; Journell et al., 2013) while others discussed hashtags among other 
results and topics in their article (e.g., Krutka, 2013; Taylor \& Weigel, 2016). Those articles focused on hashtag use generally portrayed deeper exploration of hashtags and their impact on learning. As shown in Table 1, four major themes were identified across the eight included articles. Each $X$ represents a theme's presence within each article. These themes reflected results describing the influence of hashtags on learning. The four identified themes were: (1) giving voice to students, (2) self-organization and emerging knowledge, (3) network homophily and heterogeneity, and (4) connecting to a space beyond place. Each of these areas are described in the next section.

\section{Theme Descriptions}

Giving voice to students. One theme common to all studies and articles included in this review was that of giving voice. Several studies (i.e., Gleason, 2013, 2016; Jimenez, 2016; Journell et al., 2013) discussed the prevalence of user-generated content within hashtagged discussions. As students contributed to hashtagged conversations, they took part in discussions they may not have encountered within the classroom.

There was a significant amount of user-generated content within hashtagged conversations (Gleason, 2013), and this is one form of giving voice. Hashtagged conversations provided voices that were additional, and sometimes alternative, to those available in traditional media (Gleason, 2013). This meant that students who might otherwise be excluded from discussions on world issues could contribute their voices and actively participate in these conversations (Gleason, 2013, 2018; Journell et al., 2013). Students noted that they were able to gather information that differed from what they read in books or viewed in controlled media; information came from users experiencing issues that resonated with them, sparking students to contribute their voices to the conversation (Gleason, 2018; Jimenez, 2016). In these hashtagged forums, everyone was able to contribute their voice and had a chance to be heard (Journell et al., 2014). Young people could become part of the story being told through hashtagged information (Gleason, 2016).

Table 1. Articles Mapped to Represented Themes

\begin{tabular}{|c|c|c|c|c|}
\hline Reviewed Article & $\begin{array}{l}\text { Giving } \\
\text { Voice }\end{array}$ & $\begin{array}{c}\text { Self- } \\
\text { Organization \& } \\
\text { Emerging } \\
\text { Knowledge }\end{array}$ & $\begin{array}{l}\text { Homophily \& } \\
\text { Heterogeneity }\end{array}$ & $\begin{array}{c}\text { Space Beyond } \\
\text { Place }\end{array}$ \\
\hline $\begin{array}{l}\text { \#Occupy Wall Street: Exploring } \\
\text { Informal Learning About a Social } \\
\text { Movement on Twitter (Gleason, } \\
\text { 2013) }\end{array}$ & $x$ & $x$ & $x$ & \\
\hline $\begin{array}{l}\text { New literacies practices of } \\
\text { teenage Twitter users (Gleason, } \\
\text { 2016) }\end{array}$ & $x$ & $x$ & $x$ & \\
\hline
\end{tabular}




\begin{tabular}{|c|c|c|c|c|}
\hline $\begin{array}{l}\text { Thinking in hashtags: Exploring } \\
\text { teenagers' new literacies } \\
\text { practice on Twitter (Gleason, } \\
\text { 2018) }\end{array}$ & $x$ & $x$ & & $x$ \\
\hline $\begin{array}{l}\text { Democratic Twittering: Using } \\
\text { Social Media in the Social } \\
\text { Studies (Krutka, 2013) }\end{array}$ & $x$ & & & $x$ \\
\hline $\begin{array}{l}\text { \#SayHerNameLoudly: How Black } \\
\text { Girls are Leading } \\
\text { \#BlackLivesMatter (Jimenez, } \\
\text { 2016) }\end{array}$ & $x$ & $x$ & & $x$ \\
\hline $\begin{array}{l}\text { Tweeting in the Classroom } \\
\text { (Journell, Ayers, \& Beeson, } \\
\text { 2014) }\end{array}$ & $x$ & & $x$ & $x$ \\
\hline $\begin{array}{l}\text { Joining the conversation: } \\
\text { Twitter as a tool for student } \\
\text { political engagement (Journell, } \\
\text { Ayers, \& Beeson, 2013) }\end{array}$ & $x$ & & $x$ & $x$ \\
\hline $\begin{array}{l}\text { Using Twitter for Student } \\
\text { Learning \& Connecting with } \\
\text { Scientists (Taylor \& Weigel, } \\
\text { 2016) }\end{array}$ & $x$ & & & $x$ \\
\hline
\end{tabular}

Articles presented arguments for students to share their voices, but a few articles also presented the issue of voicing without listening. When following a hashtag, one can choose with what information one will engage (Gleason, 2013) or whether one engages at all. For example, in the study by Journell et al. (2013), students participated in hashtagged discussions but rarely responded directly to classmates' contributions. There was plenty of talking, but there was little indication of listening. In another example, Gleason (2018) described one student using Twitter as a forum to tweet about her experiences as a form of journaling. This student did not intend to have a conversation with others; rather, she wanted to share the information with the world and had no intention of discussing these tweets further. Hashtagged discussions were designed to be read but not necessarily designed to foster responses (Journell et al., 2016). Hence, in some studies, students were talking "at each other" rather than "with each other" (Journell et al., 2014, p. 66). Hashtags gave students a voice, yet it may not be the case that this always produced productive discussion.

Self-organization and emerging knowledge. Hashtags were used to guide meaning-making (Gleason, 2016, 2018). That is, hashtags were often attached to statements to indicate identity, humor, and connect relevant information. This allowed participation in a collective experience while contributing to the knowledge and culture connected to the hashtag. For example, the hashtag "\#studentproblems" allows users to share their problems as students (often in an amusing way). With this hashtag, students are able to connect and organize knowledge by contributing and informing themselves of what others have contributed. The tweet "I never realized how much I needed coffee until I wrote finals \#studentproblems" voices a student's distaste for finals while also commiserating with others involved in the community. This publicly 
voices that this student believes coffee is an important key to finals success, which may prompt another user to seek caffeinated assistance in the future. Moreover, the phrase \#studentproblems connects "students" over problems that are common to their peer group, creating a community defined by the hashtag. By contributing to hashtags, students informally construct knowledge with like-minded users (Gleason, 2013).

Along with constructing knowledge, evidence also indicated that students organized and cultivated their learning with hashtags. Through hashtags, students connected with others interested in similar knowledge and actively cultivated their knowledge on a topic (Jimenez, 2016). As they connected with others, students learned to navigate hashtagged spaces, including where to go and how to behave (Gleason, 2013). Gleason (2018) called this hashtag practice "orientating" and described how some students learned to navigate these spaces through mimicking others' use of Twitter. Users in these studies were able to organize learning spaces for (and help orientate) others wanting to connect with certain information using hashtags. Hashtags alerted readers to new or relevant information (Gleason, 2016), which allowed students in studies such as Jimenez $(2016)$ and Journell et al. $(2013,2014)$ to learn to navigate informal learning spaces. For example, in Jimenez (2016), students explained that they were able to learn about a topic by following hashtags similar to those to which they were introduced (e.g., \#BlackLivesMatter). In doing this, these students organized their knowledge and found spaces to which they wanted to contribute, such as \#IfIDieinPoliceCustody. Hashtags provide an effective way of organizing the informal learning space offered by social media.

Network homogeneity and heterogeneity. In discussing organization, articles also raised ideas regarding the homogeneity and heterogeneity of networks and information. Studies noted that hashtags could present a variety of opinions and sources with which to explore and learn about a topic (Gleason, 2013; Journell et al., 2013, 2014). This aspect of hashtagged conversations deviates from the traditional school model; unlike the homogeneous networks formed in schools by peer pressure, a hashtagged discussion could expose students to diverse opinions and a variety of beliefs (Journell et al., 2014). By accessing hashtagged conversations, students connected with individuals from a variety of political and social orientations (Journell et al., 2013). However, disinterest may prevent students from accessing a variety of topics (Gleason, 2013, 2016). Put simply, we click on what we find interesting. In Gleason's (2016) study, students used hashtags to identify with groups around a shared interest. This self-directed interest, combined with personalized search results driven by online data mining, "may result, paradoxically, in information-sharing practices [in hashtagged spaces] that are less diverse than desired" (Gleason, 2013, p. 968). Studies indicated that access to diverse views was a benefit to using hashtagged spaces, presumably formed due to the high volume of user-generated content, but these discussions may not encourage accessing this diversity as students can choose with which information to interact.

Connecting to a space beyond place. Finally, articles highlighted the ability of hashtagged conversations to connect users. This connection is unique because these conversations can "eliminate geographical barriers and connect students to people with whom they would not 
normally interact" (Journell et al., 2013, p. 477). Activities such as "live-tweeting" an event, where a user or group of users describe an event at the moment it is occurring through a coconstructed story, brought together users who were both involved in the event and participating remotely (Gleason, 2018). Using live-tweeting, Gleason's student participants mobilized information across a large physical distance using connections. Again, this speaks to the potential of a diverse, heterogeneous network that is external to physical connection; connections beyond their immediate proximity allowed students to share their messages much further than they would be able to without social media (Gleason, 2018; Jimenez, 2016). This space gives participants of hashtagged conversations a place to "put it out there," a place to share their voices, stories, and lives with people without the limits of physical location (Jimenez, 2016). This space became more than proximity; it opened the realm of connection to a worldwide forum of other users interested in the same hashtagged space.

Hashtagged conversations altered the need for geographical connection, providing a new temporality within which students interacted. Studies and articles focusing on student and classroom interactions with Twitter noted that students could discuss issues in real-time instead of being limited to allotted class time (Journell et al., 2013, 2014; Krutka, 2013; Taylor $\&$ Weigel, 2016). Contributors to hashtagged conversations connected to a worldwide audience where information is shared instantaneously. This connection to a unique temporal and digital space provided a different style of conversation and may permit different types of connection.

\section{What Can the Hashtag Teach Education?}

The hashtag offers social media users a way to connect and organize online. Hashtagged conversations endorse user-generated content among traditional media, connecting meaning to users' dialogue and users to meaning. How can these ideals apply to classrooms beyond the use of social media? In this discussion, review findings are used to theorize about how hashtag ideology may influence the K-12 classroom.

Talking with and talking at. In a traditional classroom, the instructor often talks "at" students, yet teachers are encouraged to talk "with" students. Aligning ourselves to what Reed (2013) calls Web 2.0 culture, where information shifts from domain-controlled to user-controlled information, could bring this change to the classroom. To achieve this, an instructor may use a decentralized approach, as described by Newell (2008), where the teacher is no longer the single connection point for all students but one connection point in a net of connections. Students are no longer the recipients of information but active constructors within the educational network of this classroom.

Perhaps it is time for education to initiate movement from a centralized, traditional structure to one reflecting Web 2.0 values. If user-generated content is to become the educational norm, as hashtag ideology suggests, the traditional roles of teacher and student need to be addressed. The user-generated content of hashtagged conversations replaces the need for traditional, often monistic, media-led discussions (Jimenez, 2016); educators might consider shifting their 
Watson, E. (2020). \#Education: The Potential Impact of Social Media and Hashtag Ideology on the Classroom

classrooms from centrally controlled, traditional content to student-generated content. According to the articles reviewed in this study, students are often excluded from discussions, but they desire to contribute. It may be time to re-think who decides what knowledge is important.

Hashtag ideology suggests that students should contribute to curricular decisions; however, this is certainly not the norm in our current educational system where curricular decisions are made for students. One argument against student-generated content is that government bodies hold content authority-we have a curriculum document to teach! Teachers are asked to make learning student-centered while teaching externally defined curricula. Defining content and skills can impede student-driven learning (Cumberbatch \& Trujillo-Pagan, 2016). We may run the risk of disengaging students from education by formally structuring what they can (and should) learn (Miles \& Mangold, 2012; Reed, 2013). Hence, if we are to embrace the ideals of user-generated content and decentralized instruction, it may be time to rethink our educational structure and who should make decisions on what is taught.

There is also a danger in decentralizing the classroom: talking without listening. Hashtagged conversations do indeed encourage voice, but they do not always encourage conversation (Gleason, 2013; Journell et al., 2013, 2014). In the classroom, this could manifest as students shouting random thoughts without connection to other students' contributions -in other words, a classroom discussion gone terribly wrong. As educators, we encourage students to listen and thoughtfully respond, but this can be neglected in hashtagged conversations. As students live in a hashtagged world, teachers need to make the effort to teach students how to talk with each other, not at each other. While encouraging student voice and user-generated content, education should also ensure that students are able to converse instead of simply talk.

By applying hashtag ideology, educators may move closer to student-centered teaching, inspiring students to converse instead of always reporting to a central node, the teacher. The decentralized classroom encourages user-generated content and offers alternative learning avenues to a monistic curriculum. Finally, it is important that students learn to listen, a skill not required by hashtagged conversations; teachers need to not only provide space to talk with others but also encourage (and teach) thoughtful responses. Education should prepare students to be active participants in their world. Perhaps hashtag ideals can provide the voice students need to actively contribute to education systems.

Constructivist classrooms and self-organization. Commenting on sources from both media and users, participants in a hashtagged conversation contribute to and co-construct knowledge. This resonates with constructivist classrooms, where learners are actively involved in both meaning-making and knowledge construction. In the constructivist classroom, knowledge emerges as our students participate in the world (Osberg \& Biesta, 2008). Social constructivism, where meaning is constructed within a social group, is particularly integral to hashtag ideology. If we are to teach our students in line with Web 2.0 ideals, constructivism should take a more central seat in the educational conversation. 
In the constructivist classroom, students connect, organize, and produce knowledge, just as is done in hashtagged conversations. Hashtagged spaces encourage users to think not only about what information they are interacting with, but also how this information is organized within the hashtagged space (Bates, 2013). As mentioned by Gleason (2013, 2018), Jimenez (2016), and Journell et al. (2013, 2014), students learn through hashtag use to navigate informal learning spaces. One aim of constructivist teaching is to have students learn to effectively learn (Matthews, 1994); hashtag ideology would agree, implicating that it is more important that students are taught to navigate learning than to focus on learning information.

Again, this incites consideration of pre-determined course curricula and what should be taught. Empowering students to make decisions about how they learn allows students to decide how they connect to the learning, how they connect ideals, with whom they want to learn, and to control their learning (Hall, 2009). This encourages autonomous learning, urging students toward becoming what Illich (1977) called self-aware actors who ask questions of what and how they are learning. "We are constantly being taught, constantly learn, and constantly unlearn" (Sandlin, 2010, p. 1), so why limit ourselves to focusing on what information to learn? If we are constantly learning, the classroom should focus on teaching skills needed to learn instead of impressing subject content on learners. Constructivism, as informed by selforganization and learning to navigate spaces, may provide learners with these metacognitive skills.

Our curricula have specific concepts, written from specific perspectives, to be learned; this does not leave much room for constructivism. If curricular documents are indicators of content to be covered in a course, this is arguably a significant issue. However, if curriculum documents were written to provide teachers with the freedom to explore topics instead of aiming for students to learn a pre-destined set of information, this problem may cease. As an example of how this may be attempted, consider the science curricula in Saskatchewan, Canada. In these documents, teachers are given broad outcomes that students are supposed to learn; for example, in the Physics 30 document, students are to learn to "analyze the effects of forces on objects undergoing uniform motion, uniformly accelerated motion and circular motion" (Government of Saskatchewan, 2017, p. 30). This statement provides significant room for teachers to explore this concept. However, acceptable conceptions are not only driven by the curriculum but also by discipline-specific understandings (Kuhn, 1996). For example, experts in physics will likely explain the effects of forces on objects in these three frames of motion in a consistent format since these are accepted understandings in physics. Hence, even though the curriculum document is open to constructive approaches, the teacher is still limited by understandings accepted in a discipline. On top of these limitations, many school systems across the globe require students to write standardized exams at the end of certain courses, further limiting the teacher to what content has to be learned. Requiring specific knowledge to be taught, along with standardization of tests and classroom practice, makes it difficult to constructively teach. Hashtagged spaces teach students how to learn, not what to learn; perhaps classrooms need to reorient to meet those ideals of the spaces with which students interact. 
The dangers of homogeneity. Reviewed articles discussed the availability of a diverse, heterogeneous network in hashtagged spaces, but there is also potential for homogeneous spaces to reify existing opinions and ideas. Gleason (2013) highlights that self-interest may direct a lot of what is learned since participants in these spaces select from what sources they want to learn. It may be that participants of a hashtagged conversation are looking for what they want to hear (Bates, 2013), to interact with those of the same opinion. As an example of the dangers of these homogeneous networks, Supovitz et al. (2017) explain social media's impact on teacher network formation. Teachers used to discuss teaching with others in their school, district, or division; these opinions would likely vary and may have encouraged the debate of ideas. However, with social media, teachers can seek out networks of common ideals and values; they do not have to be challenged. If our students were to learn in the same way, their understandings might never be challenged. Students may not learn to think beyond their own perceptions. This is a worrisome thought, to say the least.

The classroom ought to teach students to explore diverse opinions, seek challenges, and challenge ideas. While the hashtag can promote homogeneous networks, it also provides a diverse community from which to access information (Coleman et al., 2018; Dagdilelis, 2018; Freishtat, 2010). Just as the classroom needs to provide students with the skills to learn, it must also engage students with information that challenges their beliefs, as it is in encountering belief disagreement that humans are offered the opportunity to reflect on what they know and learn from this (Christensen, 2019). With the rise of "fake news" and user-generated content, knowledge is becoming increasingly unfiltered (Supovitz et al., 2017). Education has a responsibility to teach students to navigate knowledge while also making appropriate judgements on information and its sources. Education should not provide "correct" answers that students blindly accept; education should challenge students' conceptions of what they already believe, forcing students to rethink what they think they know. It is not enough to know an answer, one must also know why that is an acceptable answer. Following hashtag ideology, teachers could encourage their students to find information and people that challenge their beliefs and ask them to reflect on their reactions to these encounters, a feat that may not be possible inside a traditional classroom. Teaching students to seek out a variety of sources when gaining knowledge may provide a better understanding of how to learn in this Web 2.0 world.

Learning beyond the classroom. Social media connects users across the world, building unique, virtual communities. A communal spirit develops through social media, fostering communities from diverse and separate individuals based on common interests (Coleman et al., 2018; Freishtat, 2010; Tully \& Ekdale, 2014). Hashtags allow users to effectively find others interested in learning about and discussing common issues of curiosity, as shown by those articles reviewed. Despite ranging in geographical distance, these communities remove the requirement of a common place to discuss ideas. Perhaps education should reconsider whether a common location is required for learning.

Much like online classrooms, the classroom of today could reach well beyond the walls we envision in schools. In a traditional school setting, students interact with knowledge at a certain 
time on certain days. Should students decide to interact with this knowledge outside of class and have a question, they must wait until the next meeting time to bring it up. With hashtagged conversations, learning can occur in real-time instead of being limited to designated class time. Perhaps the classroom should no longer be set in a certain timeframe but be allowed to permeate throughout the day. Logistically, this may seem ill-conceived since a teacher cannot possibly be expected to work all hours of the day, but hashtag-informed education is not a centralized learning experience. Through a decentralized experience, hashtag learners can (and should) interact with knowledge, with those not in their classroom, with peers, and with their teacher in real-time. The hashtag-informed teacher is no longer the container of content but a conduit facilitating learning, able to follow the conversation and contribute but not control the content. Students in a hashtag-informed classroom are not limited to a specific place and time of learning but are able to learn in real-time from a worldwide community.

Our students constantly learn beyond the classroom; through social media and hashtagged conversations, our students contribute to a global pool of constantly shifting and emerging knowledge. Hashtagged conversations offer another view of education and encourage students to develop knowledge without the formal classroom. Maybe we should question the necessity of the common classroom for learning.

\section{Conclusion}

Through a systematic review of articles discussing hashtags and hashtag use in K-12 settings, four major ideals to apply to the classroom were identified. First, the hashtag-informed classroom gives students voice and promotes user-generated content, unlike the typical, centrally dictated classrooms. This theme, along with the second theme of self-organization and emergent knowledge, beckon reconsideration of our current educational system and the use of common curriculum documents. Curriculum, the teacher, and the discipline dictate what should be learned in our current system, yet hashtag use elevates the decentralized nature of informal learning. This emphasizes a crevasse separating our students' world and the world of education. Hashtag ideology suggests that students be allowed to generate and contribute to the information to be learned, but also to organize themselves, learn to select what to investigate, and justify their learning decisions. Just as users become "orientated" (Gleason, 2018) and learn how to use the hashtag, learning in this classroom shifts focus from the content to be acquired to learning how to learn.

Hashtag ideology would suggest that the classroom be re-envisioned. Traditional classes meet during allotted times and in a specific place (whether that space is online or in-person). This limits knowledge creation to those in a similar geographical area (or online room) and specific time. However, with hashtags, students are able to investigate various topics at their own leisure. When they have a question, they pose it to a community and (hopefully) receive a response in real-time from any number of people including experts, peers, teachers, and others. These hashtag-informed principles along with student voice, user-generated content, selforganization, and learning to learn would suggest that it is time we reconsider classroom and 
education structure. Hashtagged ideology suggests ways that education systems might make formal learning fit into an informal space. It is time for education to start relating to how students are already learning: with Web 2.0 principles and hashtags.

\section{References}

Bates, M. (2013). Of hashtags and descriptors (English). Online Searcher, 37(3), 80.

Braun, V., \& Clarke, V. (2006). Using thematic analysis in psychology. Qualitative Research in Psychology, 3, 77-101.

Christensen, D. (2019). Epistemology of disagreement: The good news. In J. Fantl, M. McGrath, \& E. Sosa (Eds.), Contemporary epistemology: An anthology (pp. 231-248). John Wiley \& Sons, Inc.

Coleman, J. M., Rice, M., L., \& Wright, V., H. (2018). Educator communities of practice on Twitter. Journal of Interactive Online Learning, 16(1), 80-96.

Cumberbatch, P., \& Trujillo-Pagan, N. (2016). Hashtag activism and why \#BlackLivesMatter in (and to) the classroom. Radical Teacher, 106, 78-86.

Dagdilelis, V. (2018). Preparing teachers for the use of digital technologies in their teaching practice. Research in Social Sciences and Technology, 3(1), 109-121. Retrieved from http://ressat.org/index.php/ressat/article/view/345

Duffy, J., Wickersham-Fish, L., Rademaker, L., \& Wetzler, B. (2018). Using collaborative autoethnography to explore online doctoral mentoring: Finding empathy in mentor/protégé relationships. American Journal of Qualitative Research, 2(1), 57-76.

Freishtat, R. (2010). Constructing community, disciplining dissent: The public pedagogy of Facebook as a social movement. In Handbook of public pedagogy (pp. 201-213). Routledge.

Gleason, B. (2013). \#Occupy Wall Street: Exploring informal learning about a social movement on Twitter. American Behavioral Scientist, 57(7), 966-982.

Gleason, B. (2016). New literacies practices of teenage Twitter users. Learning, Media and Technology, 41(1), 31-54.

Gleason, B. (2018). Thinking in hashtags: Exploring teenagers' new literacies practices on Twitter. Learning, Media and Technology, 43(2), 165-180. 
Government of Saskatchewan. (2017). Physics 30 curriculum document. Regina, SK: Ministry of Education.

Gunuc, S., Misirili, O., \& Odabasi, F. (2013). Primary school children's communication experiences with Twitter: A case study from Turkey. Cyberpsychology, Behavior, and Social Networking, 16(6), 448-453.

Hall, R. (2009). Towards a fusion of formal and informal learning environments: The impact of the read/write web. Electronic Journal of E-Learning, 7(1), 29-40.

Illich, I. (1972). Deschooling society. Harper \& Row.

Jeffares, S. (2014). Interpreting hashtag politics: Policy ideas in an era of social media. Palgrave Macmillan.

Jimenez, I. (2016). \#SayHerName loudly: How Black girls are leading \#BlackLivesMatter. Radical Teacher, 106, 87-96.

Journell, W., Ayers, C., \& Beeson, M. (2013). Joining the conversation: Twitter as a tool for student political engagement. The Educational Forum, 77(4), 466-480.

Journell, W., Ayers, C., \& Beeson, M. (2014). Tweeting in the classroom. The Phi Delta Kappan, 95(5), 63-67.

Kilinc, E., Evans, R. T., \& Korkmaz, U. (2012, March). Aligning Facebook and Twitter with social studies curriculum. In P. Resta (Ed.), Proceedings of Society for Information Technology \& Teacher Education International Conference 2012 (pp. 517-521). AACE.

Kimmons, R. Carpenter, J., Veletsianos G., \& Krutka, D. (2018). Mining social media divides: An analysis of K-12 U.S. school uses of Twitter. Learning, Media and Technology, 43(3), 307-325. DOI: 10.1080/17439884.2018.1504791

Krutka, D. (2013). Democratic Twittering: Using social media in the social studies. The International Society for the Social Studies Annual Conference Proceedings, 2013(1), 7581.

Kuhn, T. (1996). The structure of scientific revolutions (3rd ed.). The University of Chicago Press.

Loomis, S. (2018). \#Twitter: A pedagogical tool in the high school classroom. Journal of Language and Literacy Education, 14(1), 1-10.

Lu, J. (2014). Twitter tries to explain hashtags. The Washington Post. 
Watson, E. (2020). \#Education: The Potential Impact of Social Media and Hashtag Ideology on the Classroom

Matthews, M. (1994). Science teaching: The role of history and philosophy of science. Routledge.

Meredith, E. (2018). Technology acceptance model and the influence of twitter on K-12 educators (Order No. 10929333). Available from Education Database; ProQuest Dissertations \& Theses Global. (2150252677).

Miles, S., \& Mangold, W. (2014). Employee voice: Untapped resource or social media time bomb? Business Horizons, 57, 401-411.

Newell, C. (2008). The class as a learning entity (complex adaptive system): An idea from complexity science and educational research. SFU Educational Review, 2(1), 5-17.

Newman, M., \& Gough, D. (2019). Systematic reviews in educational research: Methodology, perspectives and application. In O. Zawacki-Richter, M. Kerres, S. Bedenlier, M. Bond, \& K. Buntins (Eds.), Systematic reviews in educational research. Springer VS.

Osberg, D., \& Biesta, G. (2008). The emergent curriculum: Navigating a complex course between unguided learning and planned enculturation. Journal of Curriculum Studies, 40(3), 313-328.

Ramírez, B. G., \& Metcalfe, A. S. (2017). Hashtivism as public discourse: Exploring online student activism in response to state violence and forced disappearances in Mexico. Research in Education, 97(1), 56-75. https://doi.org/10.1177/0034523717714067

Reed, P. (2013). Hashtags and retweets: Using Twitter to aid community, communication and casual (informal) learning. Research in Learning Technology, 21, 1-21.

Rosell-Aguilar, F. (2018). Twitter: A professional development and community of practice tool for teachers. Journal of Interactive Media in Education, 1(6), 1-12.

Sandlin, J. (2010). Understanding, mapping, and exploring the terrain of public pedagogy. In Handbook of public pedagogy (pp. 1-6). Routledge.

Science Daily. (2017, April 21). New survey: Snapchat and Instagram are most popular social media platforms among American teens. Retrieved from:

https://www.sciencedaily.com/releases/2017/04/170421113306.htm

Stornaiuolo, A., \& Thomas, E. E. (2017). Disrupting educational inequalities through youth digital activism. Review of Research in Education, 41(1), 337-357.

Tang, Y., \& Hew, K. F. (2017). Using Twitter for education: Beneficial or simply a waste of time? Computers \& Education, 106, 97-118. 
Taylor, A., \& Weigel, E. (2016). Using Twitter for student learning \& connecting with scientists. The American Biology Teacher, 78(7), 599-602.

Tully, M., \& Ekdale, B. (2014). Sites of playful engagement: Twitter hashtags as spaces of leisure and development in Kenya. Information Technologies \& International Development, 10(3), 67-82.

Vázquez Cano, E. (2012). Mobile learning with Twitter to improve linguistic competence at secondary schools. New Educational Review, 29(3), 134-147.

Willet, S. (2019). Revisiting how and why educators use Twitter: Tweet types and purposes in \#Edchat. Journal of Research on Technology in Education, 51(3), 273-289. 